\title{
PENERAPAN METODE OLAP DALAM SIE PELAYANAN ADMINISTRASI KECAMATAN MEGANG SAKTI BERBASIS WEB
}

\author{
Refky Ari Yunanda ${ }^{1)}$, Syafri Aprudi ${ }^{2)}$ \\ ${ }^{1}$ Program Studi Sistem Informasi, STMIK Bina Nusantara Jaya Lubuklinggau \\ Program Studi Ilmu Sosial dan Ilmu Politik, Universitas Musi Rawas \\ Jalan Yos Sudarso No 97 A Kota Lubuklinggau Sumatera Selatan \\ E-mail : Refkyari@gmil.com ${ }^{1)}$, Syafriaprudi@gmail.com²
}

\begin{abstract}
Megang Sakti District Is an agency engaged in government, which provides services to the community. As one of the government agencies that provide services to the community, Megang Sakti District has a problem in data collection or reports in the field of public services in the form of family cards, identity cards, moving letters, birth certificates and death certificates that are still done manually. In the process of data collection and reporting requires a long time, inaccurate data, loss of data that makes it difficult for leaders to see the results of the report and take certain actions. To overcome this problem the authors conducted a study entitled Application of Olap Method in Administrative Services Executive Information Systems in the WebBased Megang Sakti District, with the construction of the system is expected to facilitate data collection or reports and facilitate leaders in taking certain actions. In making the system using PHP Programming Language, and supported by MySQL as a database server.
\end{abstract}

Keywords: SIE, Online Analytical Processing, District, WEB.

\begin{abstract}
Abstrak
Kecamatan Megang Sakti Merupakan instansi yang bergerak di bidang pemerintahan, yang memberikan pelayanan terhadap masyarakat. Sebagai salah satu instansi pemerintahan yang menyediakan pelayanan terhadap masyarakat, Kecamatan Megang Sakti mempunyai sebuah permasalahan pada pendataan atau laporan dalam bidang pelayanan umum berupa kartu keluarga, kartu tanda penduduk, surat pindah, akte kelahiran dan akte kematian yang masih dikerjakan secara manual. Dalam proses pendataan maupun laporan membutuhkan waktu yang lama, data yang tidak akurat, hilangnya data sehingga mempersulit pimpinan dalam melihat hasil laporan dan mengambil tindakan tertentu. Untuk mengatasi masalah tersebut maka penulis melakukan penelitian yang berjudul Penerapan Metode Olap Dalam Sistem Informasi Eksekutif Pelayanan Administrasi Pada Kecamatan Megang Sakti Berbasis Web, dengan dibangun nya sistem tersebut diharapkan dapat mempermudah pendataan atau laporan serta mempermudah pimpinan dalam mengambil tindakan tertentu. Dalam pembuatan sistem tersebut menggunakan Bahasa Pemrograman PHP, serta didukung MySQL sebagai database server.
\end{abstract}

Kata kunci: SIE, Online Analitycal Processing, Kecamatan, WEB.

\section{Pendahuluan}

Perkembangan teknologi informasi yang begitu pesat sekarang ini begitu terasa pengaruhnya di semua aspek di kehidupan sehari - hari manusia. Salah satunya pada organisasi bisnis yang mampu memberikan kemudahan dan ketepatan dalam pengambilan keputusan. Layaknya instansi - instansi pemerintahan yang berkembang dan kegiatannya sudah meluas mencakup kegiatan ekonomi, maka kehadiran sistem informasi sangatlah penting. Saat ini informasi dibutuhkan baik di instansi pemerintahan maupun swasta, dengan kebutuhan informasi tersebut maka dengan cara membenahi sistem pengolahan data dengan komputer agar memberikan kemudahan. Pengguanaan informasi merupakan hal yang penting bagi setiap instansi - instansi pemerintahan. Salah satunya pada Instansti Kecamatan Megang Sakti, namun selama ini Instansi Kecamatan Megang Sakti masih melakukan penyerahan laporan pelayanan administrasi umum kepada pimpinan masih berbentuk hardcopy sehingga dalam melakukan pengolahan data administrasi terdapat beberapa hal yang menyebabkan lambatnya proses dalam pembuatan maupun penyerahan hasil laporan. Sebagai solusi permasalahan diatas tersebut diperlukan sebuah Sistem Informasi Eksekutif untuk pembuatan hasil laporan administrasi, sehingga laporan yang dihasilkan akan terorganisir. Maka perlu dilakukan manajemen data pada administrasi pelayanan umum tentang pendataan laporan kartu keluarga, kartu tanda penduduk, akta kelahiran, akta kematian, dan surat pindah. Skema yang digunakan yaitu skema star, dan terdapat data fakta pelayanan umum, data dimensi jenis pelayanan, dan data dimensi desa. Metode yang digunakan adalah OLAP (Online Analytical Processing).

Sistem Informasi Eksekutif didefinisikan sebagai sebuah sistem berbasis komputer yang memungkinkan manajer senior untuk mengakses sumber informasi internal dan eksternal yang telah diringkas ke dalam tampilan grafik yang mudah diakses, 
Sistem informasi eksekutif dapat ditampilkan dalam mudah. Rotasi dapat dilakukan dengan memutar bentuk dashboard yang terdiri atas grafik dengan masing-masing sumbu dari cube yang dikehendaki kapabilitas[1]. untuk menampilkan data dari berbagai sudut pandang.

Adapun tujuan dari penelitian ini adalah membangun b. Slicing dan Dicing

sistem dengan menerapkan sebuah metode OLAP Operasi slicing dan dicing merupakan kemampuan (Online Analytical Processing) pada kecamatan megang OLAP untuk melakukan pemilihan subset pada suatu sakti berbasis web. Dengan adanya sistem tersebut data. Proses slicing adalah proses pemotongan data pada diharapkan dapat memberikan manfaat yaitu cube berdasarkan nilai pada satu atau beberapa dimensi. memudahkan pihak desa dalam melakukan manajemen Sedangkan dicing adalah pemotongan hasil slicing data administrasi khususnya pada pelayanan umum menjadi bagian subset data yang lebih kecil.

tentang pendataan laporan kartu keluarga, kartu tanda

penduduk, akta kelahiran, akta kematian, dan surat c. Drill Down dan Consolidation

pindah. dan dapat membantu kepala desa dalam Operasi ini merupakan proses agregasi data. Proses drill mengambil keputusan untuk peningkatan layanan down adalah proses penampilan data dalam bentuk yang administrasi yang ada di setiap desa pada kecamatan lebih detail. Proses pendetailan ini berdasarkan konsep Megang Sakti Kabupaten Musi Rawas.

\section{Tinjauan Pustaka}

\subsection{Sistem Informasi Eksekutif}

Sistem Informasi Eksekutif (EIS) adalah sebuah sistem yang menyediakan informasi secara cepat bagi eksekutif Pada penelitian terdahulu yaitu Peningkatan Jumlah atas keseluruhan kinerja perusahaan serta membantu Pengguna Layanan Jasa Hotel Melalui Penerapan Bisnis eksekutif dalam mengambil keputusan yang tepat. Intelijen dengan Teknik OLAP yaitu menghasilkan Sistem informasi eksekutif merupakan salah satu sistem sistem yang bertujuan untuk memberikan manfaat yaitu informasi yang sangat dibutuhkan untuk manajerial memudahkan pihak manajemen hotel dalam perusahaan saat ini[2]. Modul sistem informasi eksekutif menganalisis informasi mengenai perkembangan jumlah ini diperuntukkan bagi top-level management dalam pengguna layanan jasa hotel[8], sedangkan menurut mengontrol dan mengawas kinerja perusahaan yang dimara kusuma hakim dalam penelitianya dengan judul dipimpinnya secara ringkas, terintegrasi, mudah Implementasi Online Analytical Processing (OLAP) dipahami, dan dalam berbagai tingkatan rincian[3]. Sistem Informasi Manajemen Perijinan. Dengan teknologi ini dapat membantu untuk pembuatan laporan jenis "rekap" dan pada data dengan ukuran besar,

\section{2. $\quad$ Online Analytical Processing (OLAP)} teknologi OLAP layak untuk dipertimbangkan untuk Online Analytical Processing merupakan perpaduan menggantikan teknologi pelaporan konvensional[9]. dinamis analisis dan gabungan dari data multidimensional dalam jumlah yang besar. OLAP merupakan kumpulan aturan yang menyediakan sebuah Adapun metodelogi penelitian yang digunakan adalah kerangka dimensional untuk mendukung pengambilan seperti pada gambar 1 sebagai berikut.

keputusan[4]. OLAP juga merupakan sebuah pendekatan secara cepat menyediakan jawaban-jawaban terhadap kueri analitik yang multidimensi[5]. OLAP adalah bagian dari kategori yang lebih global dari pemikiran bisnis, yang juga merangkum hubungan antara pelaporan dan penggalian data[6]

\subsection{Operasi Pada OLAP (Online Analytical Processing)}

OLAP dikenal memiliki banyak keunggulan dalam pengolahan data. Dengan keunggulan-keunggulan tersebut, user akan mendapatkan informasi yang diinginkan dengan berbagai format dengan mudah. Berikut adalah operasi-operasi yang terdapat pada OLAP yang merupakan keunggulan dalam proses analisa OLAP[7].

\section{a. Pivoting}

Pivoting adalah kemampuan OLAP untuk mengubah berbagai sudut pandang data. Dengan operasi ini perubahan perspektif sudut pandang menjadi lebih

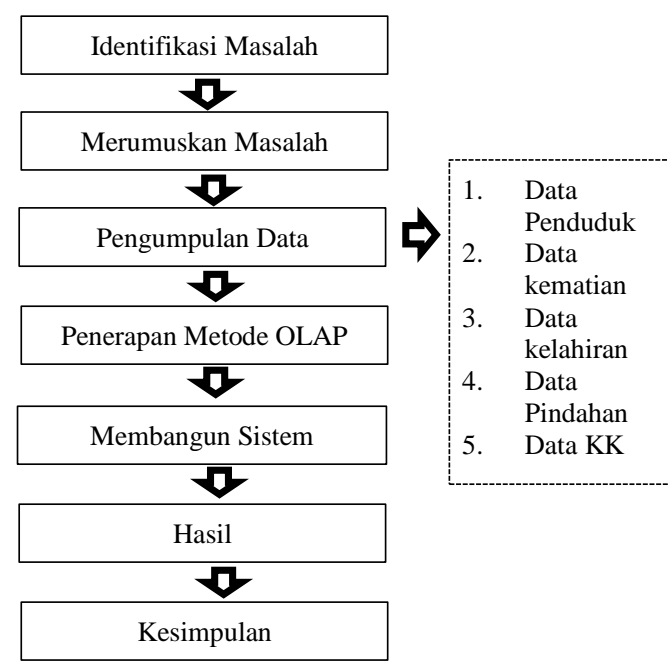

Gambar 1. Metodelogi Penelitian 
Pada tahapan 1) identifikasi masalah dilakukan diawali dengan proses observasi dan wawancara yang dilakukan pada pihak kecamatan megang sakti tentang pelayanan administrasi, kemudian tahapan 20 merumuskan permasalahan yang akan diselesaikan dengan membangun sistem informasi eksekutif yaitu Sistem informasi dengan metode OLAP tentang pelayanan administrasi pendataan laporan kartu keluarga, kartu tanda penduduk, akta kelahiran, akta kematian, dan surat pindah. tahapan 3) yaitu pengumpulan data dengan menggunakan metode penggunaan sampel yaitu data sampel yang digunakan adalah data penduduk, data kematian, kelahiran dan penduduk pindahan pada tahun 2019. Tahapan 4)penerapan Metode OLAP untuk membangun SIE yang akan digunakan sebagai manajemen pengolahan data yang dibutuhkan oleh level pimpinan. Tahapan 5) membangun sistem dengan menggunakan bahasa pemrograman PHP dan database Mysql. Tahapan 6) hasil dari sistem yang telah dibangun. Tahapan 7) adalah sistem yang dibangun dapat memberikan manfaat baik pihak kecamatan megang sakti khususnya pada pimpinan di kecamatan megang sakti Kabupaten Musi Rawas.

\section{Hasil dan Pembahasan}

\subsection{Hasil Analisis dengan Skema OLAP}

Pada skema OLAP ini menggunakan skema star, dimana terdapat data fakta pelayanan umum, data dimensi jenis pelayanan dan data dimensi jenis desa yang mencakupi 5 data yaitu Kartu Keluarga, Kartu Tanda Penduduk, Surat Pindah, Akta Kelahiran, Akta Kematian yang digunakan dalam menampilkan hasil laporan yang berdasarkan id layanan, tanggal pelayanan, id desa, id jenis pelayanan dan jumlah. Berikut gambar dari skema star.

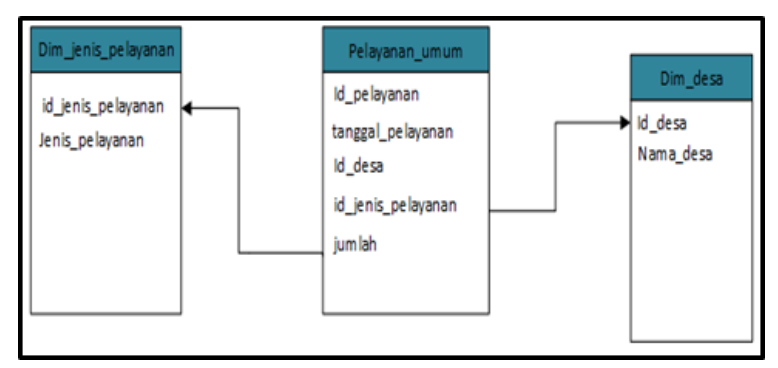

Gambar 2. Skema OLAP

\subsection{Perancangan Sistem}

\section{a. Usecase Digaram}

Pada tahap perancangan sistem menggunakan model perancangan UML seperti pada gambar 4 dan 5 yaitu perancangan model Usecase admin dan pimpinan sebagai berikut :

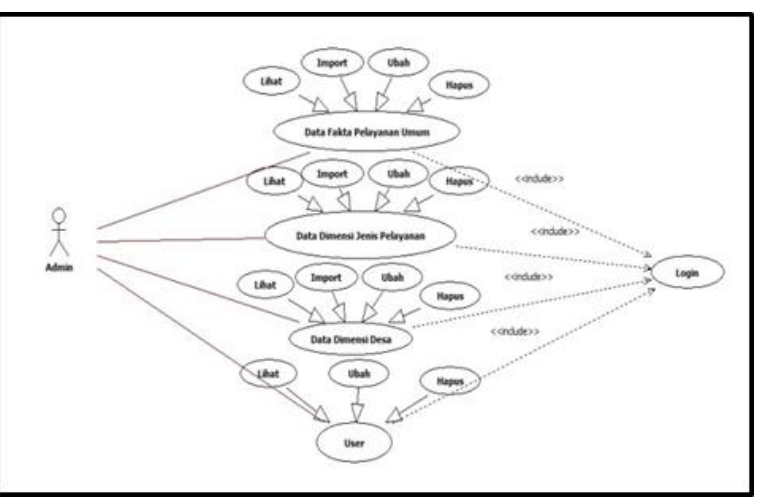

Gambar 3. Usecase Diagram Admin

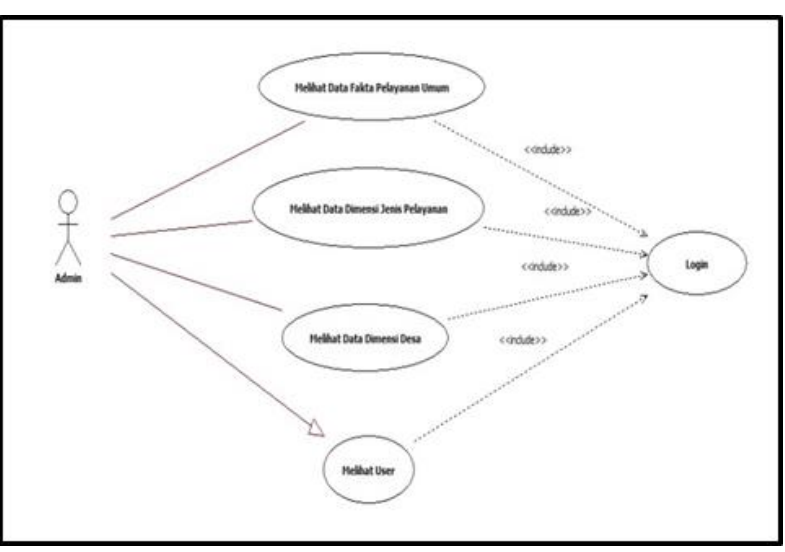

Gambar 4. Usercase Diagram Pimpinan

b. Class Diagram

pada tahapan perancangan berikutnya menggunakan class diagram yaitu bertujuan untuk menentukan entitas yang akan digunakan dalam membangun sistem informasi eksekutif dengan metode OLAP. Adapun class diagram dapat dilihat pada gambar 6 sebagai berikut :

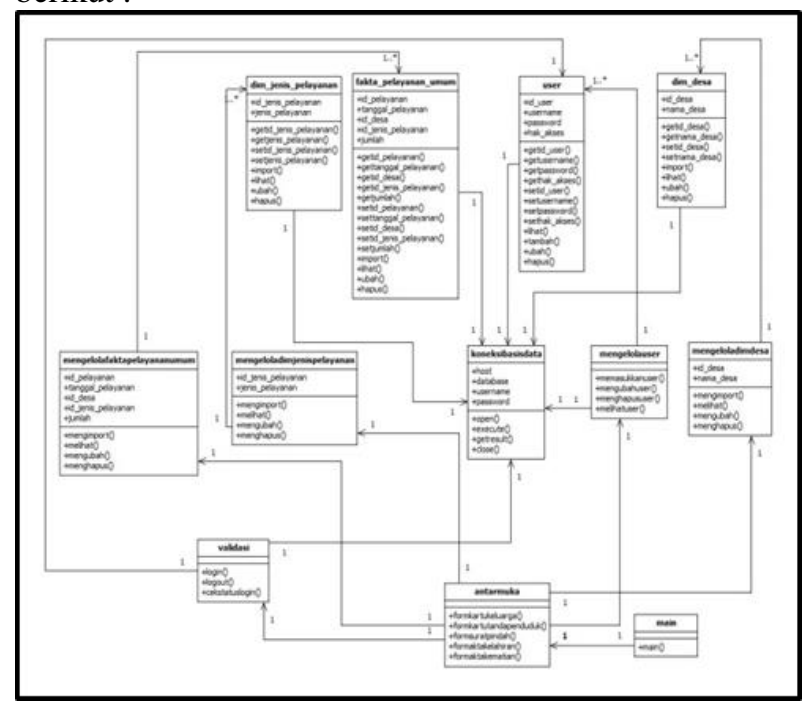

Gambar 5. Class Diagram

\subsection{Implementasi Sistem}

a. Arsitektur Sistem

adapun aktivitas yang dapat dilakukan pada sistem yang telah dibangun dapat diketahui melalui gambaran

Jurnal Ilmiah Binary STMIK Bina Nusantara Jaya

Vol. 02 No. 02 Tahun 2020, ISSN : 2657-2117 
arsitektur yang telah dibuat seperti pada gambar 7 sebagai berikut :

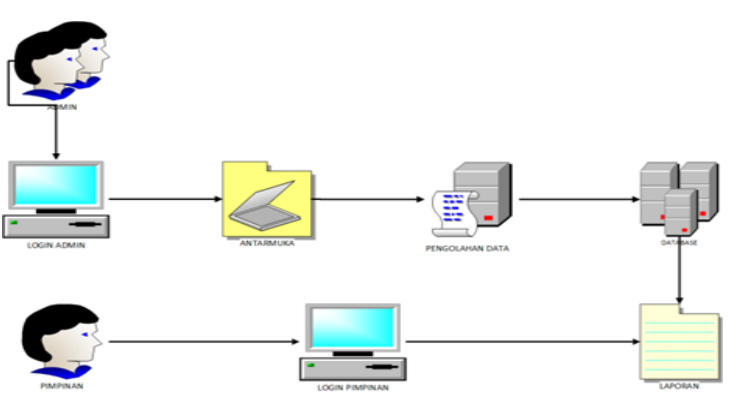

Gambar 6. Arsitektur Sistem

b. Halaman Login

Pada halaman login ini admin harus melakukan login terlebih dahulu untuk masuk kedalam sistem informasi eksekutif. Username dan password digunakan untuk login atau masuk ke aplikasi jika pengguna sudah terdaftar kedalam sistem tersebut seperti pada gambar 8 .

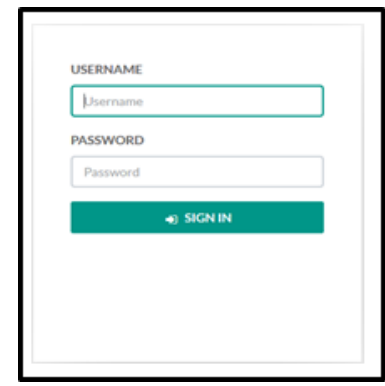

Gambar 7. Halaman Login.

\section{c. Halaman Administrator}

Pada halaman administrator dapat melakukan pengolahan data pelayanan umum, jenis pelayanan, desa, user, import pelayanan umum, import jenis pelayanan, dan import desa serta menu logout untuk keluar dari sistem seperti pada gambar 9.

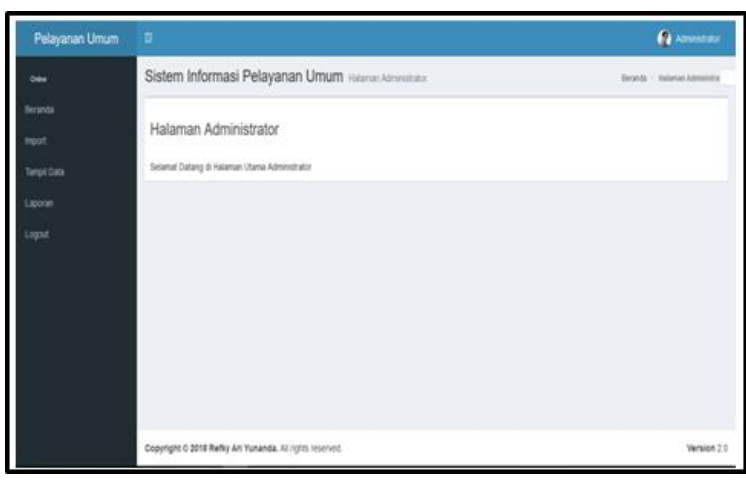

Gambar 8. Halaman Administrator

d. Halaman Laporan Data Fakta Pelayanan Umum Pada halaman ini terdapat laporan untuk pimpinan, dimana data yang sudah dilakukan atau di proses seperti malakukan pengambilan data di excel, kemudian di lakukan pengimporan data pada halaman import.
Sesudah itu ada beberapa button seperti tahun pilihan, jenis grafik, dan proses, dimana setiap button berfungsi untuk menampilkan pilihan yang diinginkan oleh eksekutif. Berikut laporan untuk eksekutif seperti pada gambar 10 sebagai berikut.

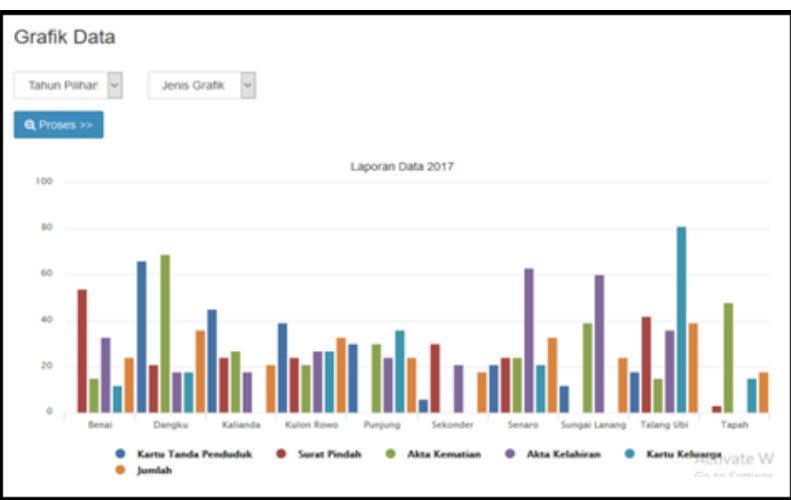

Gambar 9. Halaman Data Fakta Pelayanan Umum

\section{Kesimpulan}

5.1 Simpulan

Berdasarkan penelitian yang telah dilakukan di Kecamatan Megang Sakti pada Pelayanan Umum, maka penulis dapat menarik kesimpulan bahwa:

1. Sistem informasi eksekutif pelayanan umum kecamatan megang sakti saat ini menggunakan metode OLAP yang dapat menampilkan informasi untuk pimpinan secara akurat, sehingga pimpinan dapat mengambil keputusan.

2. Dihasilkan sistem informasi eksekutif pelayanan umum pada kecamatan megang sakti yang dapat menampilkan informasi mengenai pelayanan umum berbasis web, sehingga dapat meningkatkan kinerja admin dalam segi pelaporan kepada ekekutif sehingga dapat menghasilkan keputusan dan kebijakan mengenai pelayanan umum pada kecamatan megang sakti yang lebih baik lagi

\subsection{Saran}

Pada pengembangan selanjutnya sistem informasi pelayanan umum kecamatan megang sakti ini dijadikan online agar lebih mempermudah eksekutif dalam memonitoring dan mengambil keputusan.

\section{Daftar Rujukan}

[1]. Isa, I.G.T, dan Hartawan, G.P., 2017 Perancangan Aplikasi Koperasi Simpan Pinjam Berbasis Web (Studi Kasus Koperasi Mitra Setia), Vol. 5. ISSN: 2088-6969

[2]. Lenti Febri Nova., 2014 Rekayasa Database Terdistribusi Pada Layanan Pemesanan Tiket Pesawat Terbang, JURNAL TEKNOLOGI TECHNOSCIENTIA Vol. 6, No. 2, ISSN: 19798415

Jurnal Ilmiah Binary STMIK Bina Nusantara Jaya Vol. 02 No. 02 Tahun 2020, ISSN : 2657-2117 
[3]. Shalahudin M, Rosa A.S, 2013, Rekayasa Perangkat Lunak Terstruktur dan Berorientasi Objek, INFORMATIKA: Bandung.

[4]. Shiddiq, S. dan Pradnya, W.N., 2013 Sistem Informasi Akademik dan Administrasi SDIT ARRAIHAN Bantul, Jurnal Ilmiah DASI Vol. 14, No. 04, ISSN: 1411-3201.

[5]. Sumarna, A.H, dkk., 2017 Sistem Informasi Eksekutif PT Bank Perkreditan Rakyat Kartamulia Bandung, Prosiding SNATIF ISBN: 978-6021180-50-1.

[6]. Supriyatna, Adi., 2016 Sistem Analisis Data Mahasiswa Menggunakan Aplikasi Online Analytical Processing (OLAP) Data Warehouse, Jurnal Pilar Nusa Mandiri Vol. 12, No. 1, ISSN: 1978-1946.

[7]. Tresnawati, E, dan Susilowati E., 2014 Implementasi Teknologi OLAP Pada Sistem Pengolahan Data Penjualan, Seminar Nasional Sains dan Teknologi ISSN: 2407-1846.

[8]. Priyanti, D., Iriani., S., 2013, Sistem Informasi Data Penduduk Pada Desa Bogoharjo Keccamatan Ngadirojo Kabupaten Pacitan, Indonesian Journal Of Network and Security, Vol. 2 No. 4, ISSN : 2354-6654.

[9]. Laksana., T.G., Permata., D.I., 2016, Peningkatan Jumlah Pengguna Layanan Jasa Hotel Melalui Penerapan Bisnis Intelijen dengan Teknik OLAP (Online Analytical Process), Seminar Nasional Pendidikan Teknik Informatika, 27 Agustus 2016, ISSN 2087-2658. 